Historic, archived document

Do not assume content reflects current scientific knowledge, policies, or practices. 



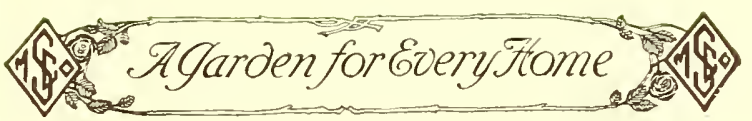

\section{The whole Truth about}

\section{Good Seeds}

\section{Published by}

MULLER-SEALEY CO., INC. HORTICULTURAL SPECIALISTS

145 West 45th Street New York City 


\section{as compared with}

\section{the cheapness of Good Seeds?}

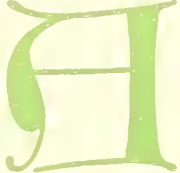

BUIER of seeds has no guarantee of their quality beyond his confidence in the integrity and reputation of the seller, together with his own knowledge of practical gardening. Seeds may be of high germination and yet be of mediocre constitution, lacking in rigor, and below standard of perfection of that particular type. In such cases, all the care and attention in the world won't produce the anticipated results.

Pedigreed Seeds are like blooded stock, they can only be produced from perfect parent plants, crossed and recrossed with finest selected and most improved types.

Such work is the life-long profession of eminent growers in countries far apart. where certain flowers and vegetables can be grown to the greatest perfection, and the seeds harvested under most desirable conditions. For instance, the finest Cabbages in the world are raised in Denmark; Cauliflowers in Germany Peas in Great Britain; Asters, Sweet Peas and Zinnias in California; France has her specialties in both Vegetables and flowers, and so on. Each class has its recognized source, not necessarily its native country, but often that of adoption, by preference. In each of these localities there are growers who have inherited family repute (over 2 or 3 generations) for the quality of the stocks they grow These men take special pains and care in keeping their stocks pure and up to a

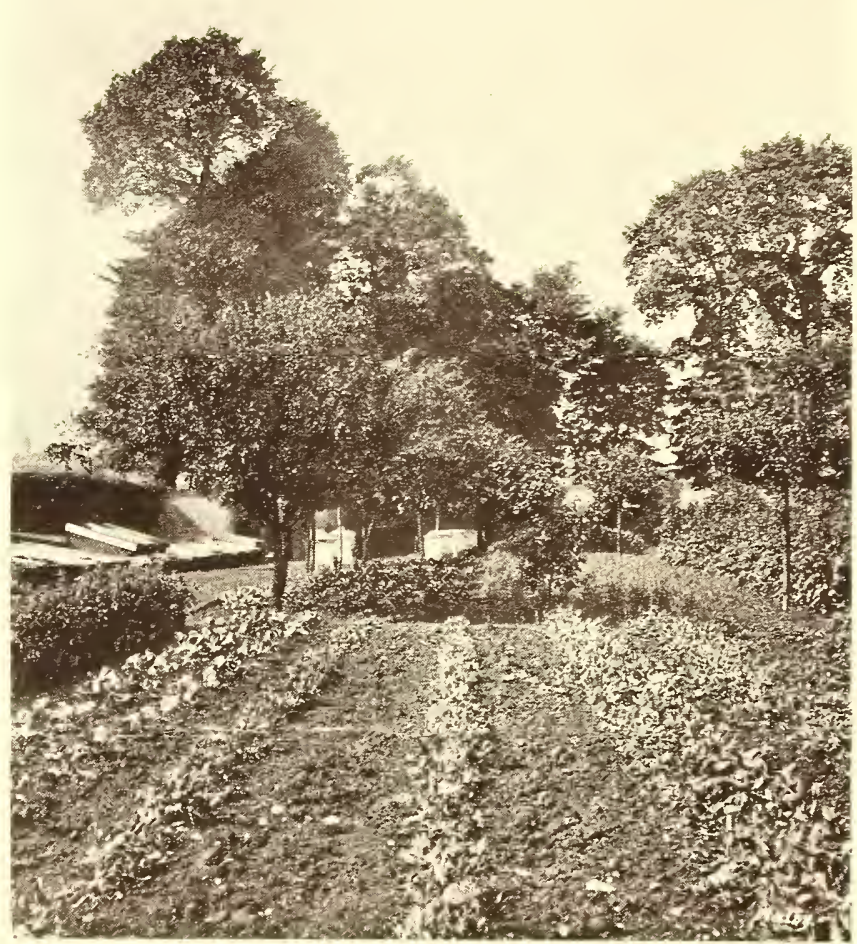

"The Garden of Plonty"

known standard of quality. Naturally they charge more than those who have no reputation to uphold, and who follow slip-shod methods of cultivation, and carelessness in cleaning, etc.

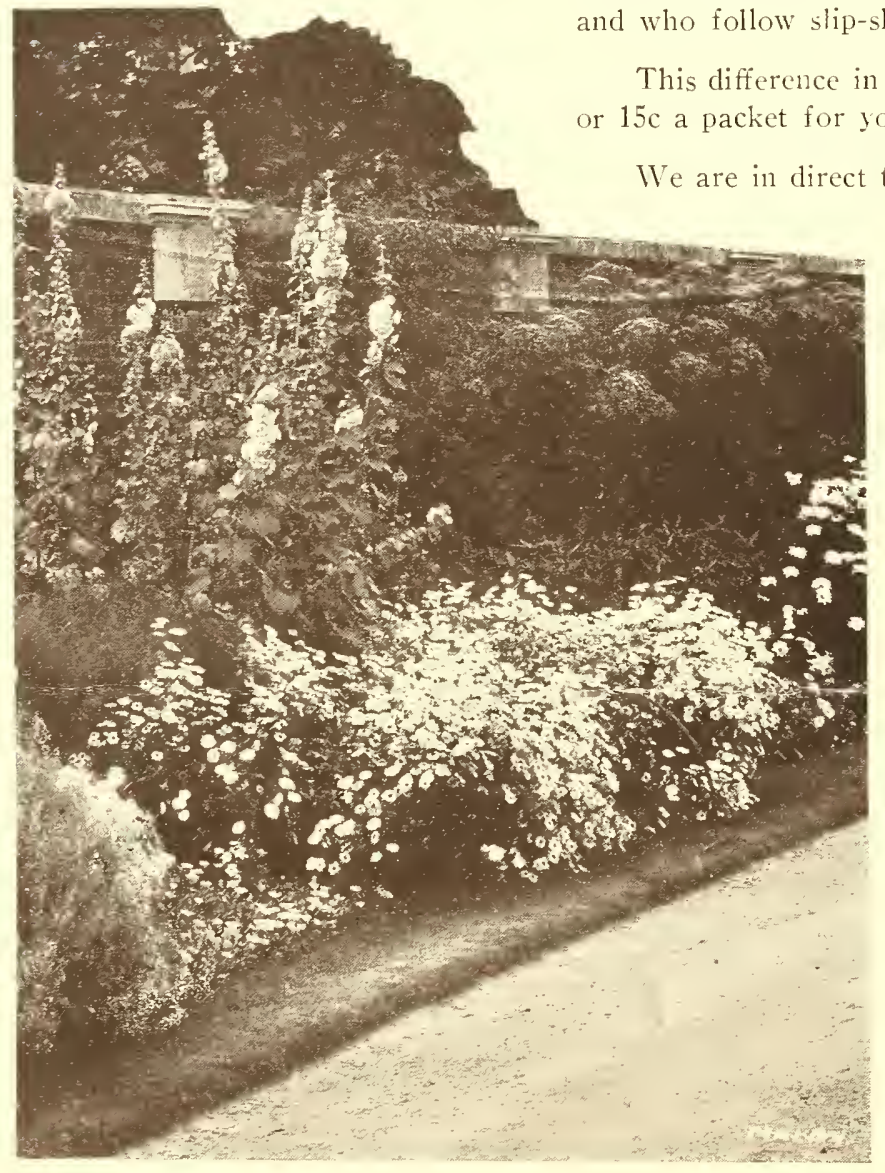

This difference in methods denotes the difference in price, and decides whether you wish to pay $5 \mathrm{c}$, $10 \mathrm{c}$, or $15 \mathrm{c}$ a packet for your Vegetable and Flower seeds for your 1924 garden.

We are in direct touch with the World's greatest growers of all classes of Seeds. Bulbs, etc. The heads of our establishment have spent many years both here and on the continent in and around the great seed growing centres, and know where the best stocks of each class are procurable.

All our foreign stocks are imported by us direct from the producers.

We are constantly advised of a new flower or an improved vegetable, and after careful trial we list or discard it. heing guided by our results under American growing conditions.

Professional and amateur gardeners who grow flowers and vegetables for profit or for pleasure and exhibition, send us their orders regularly, both for Standard Stocks and our Norelties, because they have proven our judgment to be sound, and also that they have learnt elsewhere there is much truth in the old saying "Chcap Secds aro dearest in the cud."

Our 1924 Catalog has been revised to include the finest productions of the Wrorld's most noted growers of Vegetables and Flowers, and should be studied by those who wish to have the finest in each class in their gardens. If for any reason you have not received your copy, write for it today.

"The Garden of Bcauty"

(Copyright Mullcr-Scalcy Co., Inc.)

JOSEPH A. MULLER FRANK G. SEALEY

Muller-Sealey Co., Inc. 145 West 45th Street New York Gity
"The Source of everything good that grows" 


\section{Keep This as a reminder that -}

Our direct connections with reliable sources, and recognized headquarters, enable us to fill orders promptly, and with the finest stocks obtainable, of the following-

Rare Plants of Every Description

Shade Trees

Evergreens

Deciduous Shrubs

Rhododendrons \& Azaleas

Climbing Vines

Fruit Trees

Roses

Herbaceous Plants

Rock Plants

Peonies

Irises

Dahlias

Gladioli-Lilies

Flower Seeds

Vegetable Seeds

Lawn Grass Seed

Greenhouse Plants

Fertilizers and Insecticides

All Bulbs for Autumn Planting Including the Finest

NARCISSI. TULIPS (Darwin, Cottage, Breeder and Early Varieties)

A Complete Set of Catalogs Mailed Free on Request

Dullepsealey Company Ine 145 Hest 45 istreet - Trew York

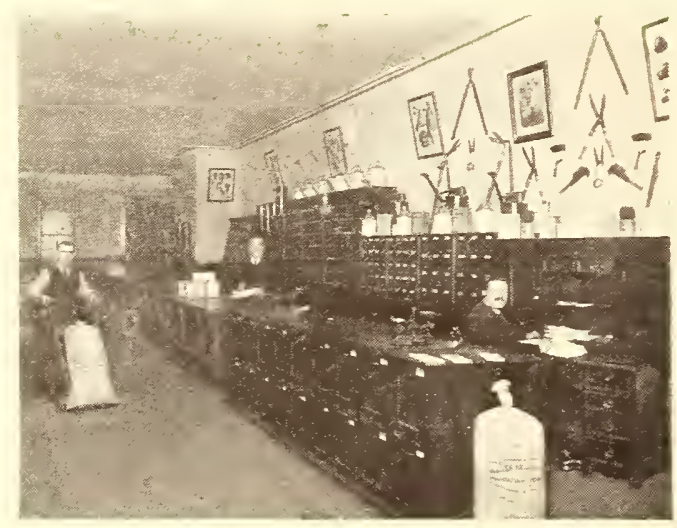

VIEW OF INTERIOR OF OUR WAREHOUSE

\section{Our Jersey City Warehouse}

Here is a view of our new warehouse at 111 Montgomery Street, Jersey City, N. J., in the heart of all great R. R. Terminals. The interior is well ventilated, and equipped with the most modern fixtures for the convenient storage of Seeds, Bulbs, Roots, and Horticultural supplies. Spacious counters and packing benches are provided for the prompt filling and shipping of orders. As we do not cater to transient trade in Jersey City, we are not handicapped in the busy season by interruptions. The warehouse is in charge of Mr.Jas. Stirling, a man of life-long expcrience in the seed trade.

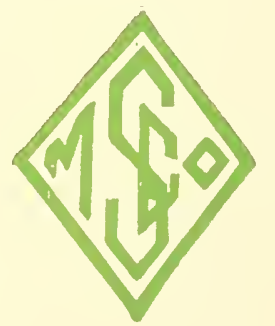

Tuller-Sealey Company.Jnc. 145 West $45 \pm$ street - ivew Zlork 